\title{
DESAFIOS À FORMULAÇÃO DE POLÍTICAS DE APOIO AO EMPREENDEDORISMO NO BRASIL: O CASO DA POLÍTICA NACIONAL DE EMPREENDEDORISMO E NEGÓCIOS (PNEN)
}

Renata Lèbre La Rovere ${ }^{1}$

Ana Beatriz Tomás Salles ${ }^{1}$

Guilherme Santos $^{1}$

Cristiano Santos ${ }^{1}$

${ }^{1}$ Universidade Federal do Rio de Janeiro 


\section{DESAFIOS À FORMULAÇÃO DE POLÍTICAS DE APOIO AO EMPREENDEDORISMO NO BRASIL: O CASO DA POLÍTICA NACIONAL DE EMPREENDEDORISMO E NEGÓCIOS (PNEN)}

Resumo: O objetivo deste artigo é discutir os desafios à formulação de políticas de apoio ao empreendedorismo, que são necessárias em ambientes pouco favoráveis à atividade empreendedora como o ambiente brasileiro. $\mathrm{O}$ artigo utiliza a metodologia de Avaliação em Profundidade para analisar o caso da Política Nacional de Empreendedorismo e Negócios (PNEN), discutindo os principais elementos de uma política de apoio e as interfaces verificadas entre o desenho da política e o contexto do país. O artigo está dividido em sete seções. A seção 1 introduz a problemática das políticas de apoio ao empreendedorismo. A seção 2 apresenta a metodologia de análise do artigo. A seção 3 apresenta uma revisão da literatura sobre os desafios às políticas de apoio ao empreendedorismo. A seção 4 apresenta o contexto da formulação da política e a seção 5 a análise do processo de formulação da política. A seção 6 discute os resultados encontrados e a seção 7 traz as considerações finais e sugestões para estudos futuros.

Palavras-chave: Empreendedorismo. Políticas de Apoio. Inovação. PNEN.

\section{Introdução}

O desenho de políticas de apoio às empresas parte do pressuposto de que estas nem sempre possuem as capacidades necessárias para ser competitivas (Parker e Hine, 2015). Porém, como apontado por Malerba e Torrisi (2009), existem duas abordagens principais para analisar e propor políticas públicas. A abordagem neoclássica ou ortodoxa propõe políticas para mitigar falhas de mercado; já a abordagem evolucionária é sistêmica, pois considera que não se pode focar as políticas apenas nas condições de competitividade, uma vez que a competitividade está, nos dias de hoje, fortemente ligada à capacidade de inovação das firmas e à dinâmica das indústrias.

No que se refere a políticas de apoio ao empreendedorismo, a abordagem ortodoxa parte do princípio que empreender depende de habilidades individuais (Casson, 1982) e, portanto, a solução para tornar uma economia mais empreendedora passa por uma política centrada na educação. Já a abordagem evolucionária considera que não apenas indivíduos como também empresas possuem capacidade de aprendizado (Julien, 2010) e que empreender depende não apenas de habilidades individuais como também do contexto. Neste sentido, uma política de cunho evolucionário tem uma abordagem sistêmica, buscando desenvolver capacidades de indivíduos, de empresas e de instituições e promover uma melhor articulação entre os agentes do sistema econômico (empresas e instituições).

No Brasil, o Governo tem feito vários esforços para alavancar a competitividade e a capacidade de inovação das empresas. Entretanto, o tema do empreendedorismo não tem sido alvo de políticas específicas. A última tentativa neste sentido foi o processo iniciado pelo Ministério do Desenvolvimento, Indústria e Comércio, em 2012, para a formulação de uma Política Nacional de Empreendedorismo e Negócios (PNEN).

A proposta deste artigo é analisar os resultados desse processo que, apesar de não ter tido continuidade devido às sucessivas mudanças no MDIC desde este período, foi interessante, pois buscou envolver os agentes interessados no assunto, rompendo com a tradição de formulação de políticas de cima para baixo do país.

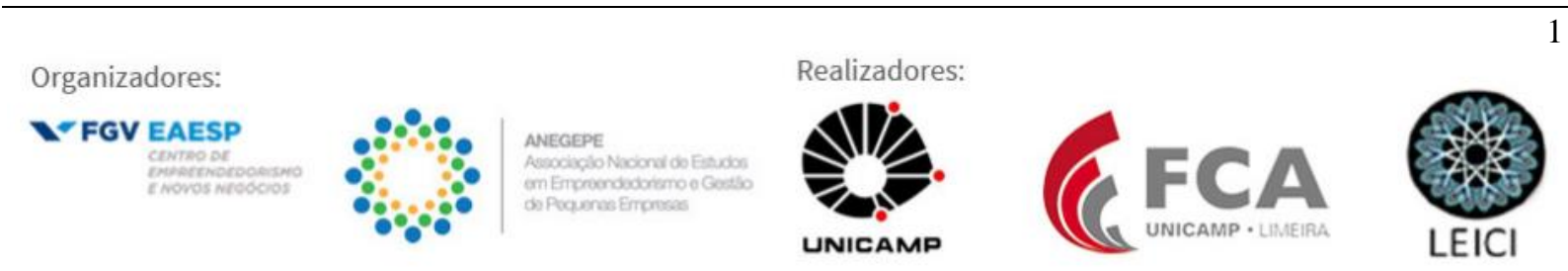


O artigo está dividido em sete seções, além desta introdução. A seção 2 apresenta a metodologia de análise do artigo. A seção 3 apresenta uma revisão da literatura sobre os desafios às políticas de apoio ao empreendedorismo. A seção 4 apresenta o contexto da formulação da política e a seção 5 a análise do processo de formulação da política. A seção 6 discute os resultados encontrados e a seção 7 traz as considerações finais e sugestões para estudos futuros.

\section{Metodologia}

Nas últimas décadas, o debate sobre Avaliação de Políticas Públicas se intensificou e envolveu diferentes atores, tais como gestores públicos, acadêmicos e avaliadores profissionais. Longe de haver um consenso, o campo se caracteriza por uma pluralidade de métodos e práticas de avaliação, que estão alicerçadas em diferentes paradigmas.

No plano hegemônico, a avaliação tradicional, ligada ao paradigma positivista, parte de uma perspectiva técnico-gerencialista e tem como objetivo medir, descrever e julgar as políticas e programas. Por outro lado, outros tipos de avaliação buscam construir alternativas a este modelo. A perspectiva crítico-dialética tem como foco a politização e a suspeição da avaliação, examinando as ideologias que embasam as políticas. O paradigma construtivista, por seu turno, parte de uma perspectiva interpretativa e propõe uma avaliação pluralista, com foco no texto da política. Buscando transcender o texto, o paradigma pós-construtivista sugere a fusão entre o texto e o contexto, tendo como base a experiência.

Com intuito de articular as contribuições dos diferentes modelos alternativos e se consolidar no campo contra hegemônico, a Avaliação em Profundidade, proposta por Gussi, (2008) e Gonçalves, (2008) pretende ser simultaneamente extensa, detalhada, ampla e multidimensional, adotando uma abordagem multi e interdisciplinar. Este modelo de avaliação estrutura-se em quatro eixos de análise principais: Análise de Conteúdo da política, Análise do Contexto em que a política foi formulada, Trajetória Institucional e Espectro Temporal e Territorial abarcado pela política.

No caso analisado neste artigo, como a Política Nacional de Empreendedorismo e Negócios não foi implementada, os eixos de análise da política serão a análise do conteúdo e a análise de contexto. Será feita também uma revisão da literatura a respeito dos desafios na formulação de políticas de apoio ao empreendedorismo, visando a fornecer elementos para a discussão do processo de formulação da política em questão.

\section{Desafios na Formulação das Políticas de Apoio ao Empreendedorismo}

A abordagem ortodoxa no desenho das políticas públicas leva seus formuladores a propor "melhores práticas" que podem ser aplicadas em diferentes contextos para estimular a competitividade das empresas. A predominância deste pensamento até meados dos anos 1990, no entender de Pessali, (2011) levou a experiências malsucedidas de aplicação de políticas de sucesso de países desenvolvidos em países em desenvolvimento. Shirley (2008) aponta que a simples "importação de instituições" não resolve os problemas que a política pública se propõe a resolver, uma vez que países em desenvolvimento estão sujeitos a dependência de trajetória e possuem conjuntos de normas e crenças que podem entrar em conflito com as instituições que a política pública importa.

O fracasso das políticas ortodoxas levou os formuladores de política de países em desenvolvimento a prestar mais atenção ao contexto local a partir de meados dos anos 1990. Porém, não basta levar o contexto em consideração; é necessário também, ao formular a

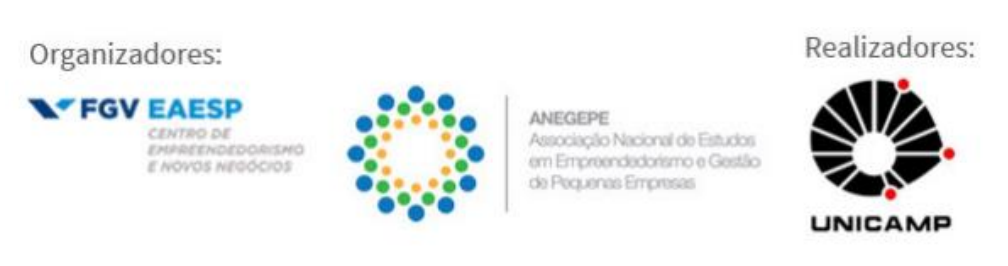


política, ouvir os atores envolvidos, o que frequentemente não ocorre (Pessali, 2011). Neste sentido, como pontuam Arshed et al. (2014), o processo de formulação pode ser uma fonte da ineficiência das políticas, uma vez que existe um fosso entre o entendimento da necessidade das políticas de apoio a empresas e como tais políticas devem ser desenhadas. Para contornar tal deficiência, a etapa de formulação de tais políticas deve ser vista como "um processo de argumentação que emerge do diálogo, interpretação, experiência e estruturas de poder vigentes" (Ram e Trehan, 2010).

Para Parker e Hine (2015) uma política bem-sucedida de apoio às empresas deve ter como objetivo estimular a inovação e o aprendizado das firmas, envolvendo gestores públicos, consultores e organizações intermediárias. Em outras palavras, a política deve ser baseada na lógica evolucionária. Se lembrarmos que a teoria evolucionária se desenvolve a partir das ideias de Schumpeter, que apontou a ligação entre empreendedorismo e inovação, podemos afirmar que uma política evolucionária de apoio ao empreendedorismo deveria fazer parte do conjunto de políticas de apoio às empresas de qualquer país que se proponha a fomentar a competividade e a capacidade de inovação de suas empresas e das instituições que formam o ambiente de inovação.

Porém, não é isso que vem sendo observado atualmente. Acs et al. (2016) constatam que a maior parte das políticas de apoio ao empreendedorismo apoia empreendedores já estabelecidos no mercado em vez de fomentar o surgimento de novas empresas.. Estes autores consideram que a regulação da criação de startups e a área de atuação destas deveriam ser objeto de políticas de apoio ao empreendedorismo, tendo como objetivo final o desenvolvimento de ambientes propícios à inovação. O conceito de startups, segundo Figueira et al. (2017), tem diferentes versões, sendo que a definição mais atual - e que será adotada neste artigo - é a de que uma startup é um grupo de pessoas que tem um modelo de negócios repetível e escalável e que trabalham em condições de extrema incerteza. É importante estabelecer o conceito porque frequentemente startups são confundidas com empresas emergentes de base tecnológica. Apesar de empresas com este perfil terem uma alta probabilidade de ser startups, por atuarem num mercado que exige altas taxas de inovação, podemos pensar em casos de empresas emergentes de base tecnológica que não são startups. Por exemplo, empresas de base tecnológica que adotam tecnologias já existentes mas são criadas em locais onde existe uma demanda não atendida, não têm um alto grau de incerteza no estabelecimento do negócio e portanto não são consideradas startups.

Cabe observar que a atividade empreendedora pode ser classificada em diferentes tipos que envolvem uma complexidade maior do que a simples dicotomia "empreendedor por necessidade" versus "empreendedor por oportunidade" adotada pelo Global Entrepreneurship Monitor. O empreendedorismo social ou de base comunitária, por exemplo, pode não ser definido por um objetivo único, como mostram Pereira e Bartholo (2015). Puri, Tavoletti e Cerruti (2015), por seu turno, sugerem que empreendedores sociais de países emergentes podem ser bastante inovadores ao explorar vazios institucionais. Assim, o foco das políticas de apoio nos países emergentes não deve se limitar a startups e ao empreendedorismo de base tecnológica, abrangendo também outras formas de empreendedorismo.

O desafio que se coloca para os formuladores de política é como migrar da cultura das melhores práticas para um pensamento mais sistêmico que leve o contexto em consideração. $\mathrm{Na}$ visão de Acs et al. (2016) este tipo de pensamento deveria fundamentar a formulação de

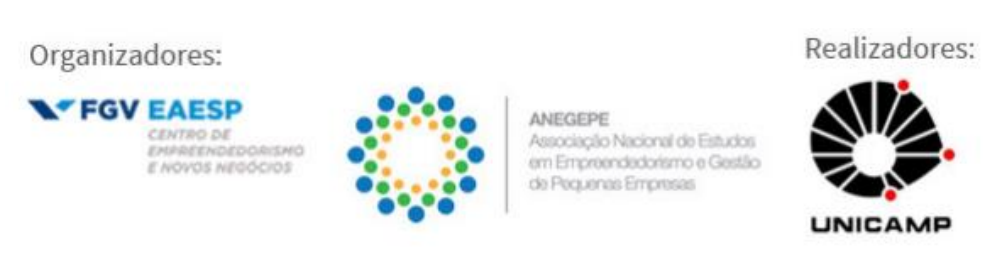


políticas públicas de apoio ao empreendedorismo. Porém, Nistostkaya e Cingolani (2016) observaram que a maior parte das políticas de apoio ao empreendedorismo é centrada no pressuposto de que a capacidade de empreender depende de habilidades individuais, na linha do pensamento ortodoxo. A abordagem destas políticas é limitada, uma vez que uma política de fomento à capacitação empreendedora centrada nas habilidades individuais é apenas um dos elementos da construção de um ecossistema de inovação bem sucedido (Arruda et al., 2015).

Uma política de apoio ao empreendedorismo precisa ultrapassar a dicotomia habilidades individuais versus contexto, valendo-se de um pensamento sistêmico. Porém, para formular uma política com base em um pensamento sistêmico é necessário conhecer a fundo o contexto e as diversas ligações possíveis entre os elementos do ambiente de inovação e adotar uma abordagem interdisciplinar na formulação de políticas. Isto porque os estudos disponíveis sobre empreendedorismo não possuem uma base conceitual única. Como observado por Ferreira et al. (2015), os estudos sobre empreendedorismo têm contribuições vindas de campos teóricos diversos, tais como Visão Baseada em Recursos, Teoria das Redes, Teoria da Agência e Economia Evolucionária.

Além dos desafios envolvidos na formulação, há também desafios ligados à implementação e ao monitoramento das políticas. Winter (2016) observa que frequentemente a justificativa para a implementação de políticas de apoio ao empreendedorismo é a criação de novos empregos; porém, as estatísticas sobre abertura de empresas não revelam a capacidade empreendedora de um país. O fortalecimento da capacidade das empresas de acessar, absorver e preservar conhecimento e de estabelecer redes, que segundo Huggins e Thompson (2015) deveria ser o objeto das políticas de apoio ao empreendedorismo. Porém, a maior parte dos países monitora a atividade empreendedora através da análise de estatísticas sobre inovação tecnológica como as disponibilizadas pela Pesquisa de Inovação Tecnológica do IBGE, a PINTEC. Além destas pesquisas frequentemente não cobrirem todos os setores e não estarem disponíveis anualmente, elas desconsideram empreendedores que não realizam atividades formais de pesquisa e de desenvolvimento.

Até recentemente, as políticas de apoio ao empreendedorismo focaram majoritariamente na entrada de mais empresas novas no mercado, reduzindo as barreiras à entrada e reduzindo os riscos de saída, aumentando, por consequência, a taxa de sobrevivência. $\mathrm{O}$ risco que se corre desta abordagem é fomentar a entrada de empresas com menor vantagem competitiva que podem não atender as expectativas por geração mais empregos. Um exemplo de política dessa natureza é o fomento ao empreendedorismo por necessidade (Shane, 2009). De modo semelhante, sobrevivência não garante crescimento. Para conseguir crescer, as empresas devem agir ativamente para adquirir capacidade organizacional (Zahra et al., 2006). Assim, é fundamental estabelecer uma cultura de empreendedores através do reconhecimento dos casos de sucesso, o que encoraja os que estão nos estágios iniciais de seus negócios.

Ainda no que se refere à implementação, delimitar o ambiente que será alvo da política de apoio é também uma tarefa complexa. Para Carlsson (2016) o ambiente empreendedor consiste de cinco componentes principais: as condições de criação e difusão de ciência e tecnologia; os mecanismos que fazem a ponte entre a base científica e as empresas (tanto novas quanto existentes); a cultura empreendedora; a infraestrutura; e o ambiente
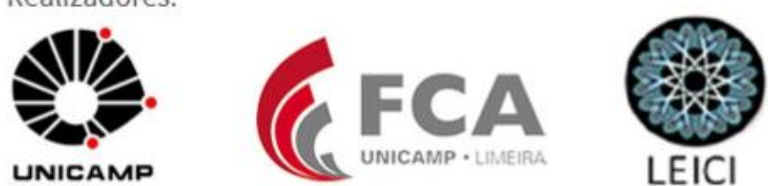
regulatório e de políticas públicas. A implementação de políticas de apoio ao empreendedorismo depende, portanto, da capacidade do Estado de coordenar diferentes programas e os diversos atores envolvidos. O desafio neste caso é não se deixar aprisionar pelas particularidades de cada política. Como observa Squicciarini (2016), a possibilidade de implementar políticas de forma coordenada frequentemente é reduzida devido à falta de resultados (de políticas anteriores) que possam ser generalizáveis. A capacidade de coordenação envolve não apenas o diálogo com formuladores de políticas de diferentes áreas como também com os agentes locais, como observado por Pessali (2011).

Neste prisma, Uyarra (2010) argumenta que as políticas públicas de apoio às empresas baseadas em uma lógica evolucionária devem ser vistas como um "todo", um sistema de políticas, ou um mix de políticas. Em outras palavras, um composto complexo que consiste em muitos elementos inter-relacionados. Estas interações são dinâmicas e dependentes da trajetória, na medida em que as políticas são adotadas não em uma tabula rasa, mas em um contexto de mixes de política e frameworks institucionais pré-existentes, os quais foram moldados através de sucessivas mudanças de políticas. Assim, as decisões de políticas passadas podem limitar o conjunto de opções para os atuais tomadores de decisão. Por isso, a formulação de uma política de apoio ao empreendedorismo deveria ter como primeiro passo uma revisão das políticas já existentes à luz dos objetivos da política em questão, para então propor uma articulação destas políticas e a criação de novos instrumentos de apoio que não se fazem presentes nas políticas já existentes.

\section{Política Nacional de Empreendedorismo e Negócios (PNEN) 4.1 Justificativas e Metodologia utilizadas}

O processo iniciado em 2012 pelo Ministério do Desenvolvimento da Indústria e Comércio em parceria com o Centro de Apoio ao Desenvolvimento Tecnológico da Universidade de Brasília foi dividido em três etapas, a saber: Formulação de teses e diretrizes, lançamento de consulta pública para legitimação das mesmas e, por fim, formulação da política propriamente dita. O documento "Elementos Estruturantes de uma Política Nacional de Empreendedorismo e Negócios" (MDIC, 2012) apresenta uma descrição do processo e dos resultados das duas primeiras etapas, ou seja, a etapa de levantamento de melhores práticas e de identificação das Teses e Diretrizes que deveriam apoiar a formulação da Política Nacional de Empreendedorismo e Negócios (PNEN) a ser lançada pelo governo ratificadas por consulta pública. Está organizado em três partes: Introdução e Contextualização, Metodologia e Principais Produtos e Apresentação das Teses e Diretrizes da Política Nacional de Empreendedorismo e Negócios.

Entre as justificativas apontadas para a realização de tal esforço, o documento cita "a necessidade de criação de um ambiente socioeconômico, político e tecnológico favorável à criação e ao desenvolvimento de empreendimentos sustentáveis" reconhecendo que, apesar do tema empreendedorismo ser parte integrante da pauta de ações de diversos órgãos e entidades, sua implementação era feita de "forma desarticulada e desconhecida por muitos" e que o empreendedorismo em si "ainda não [era] valorizado nas organizações públicas e privadas". Por fim, apontava que os impactos esperados da implantação da PNEN (Política Nacional de Empreendedorismo e Negócios) seriam: a ampliação do entusiasmo e motivação do cidadão (sic) em relação à iniciativa empreendedora responsável; a criação de condições igualitárias a todos os empreendimentos independente do porte; valorização social do empreendedor; e, por

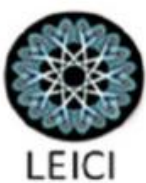


fim, a mobilização dos entes públicos em direção à simplificação do ambiente de negócios e do fomento ao empreendedorismo, conforme prevê (sic) a Lei Geral da Micro e Pequena Empresa (Lei 123/2006). A Figura 1 mostra o "organograma" da PNEN:

Figura 1: Organograma da PNEN

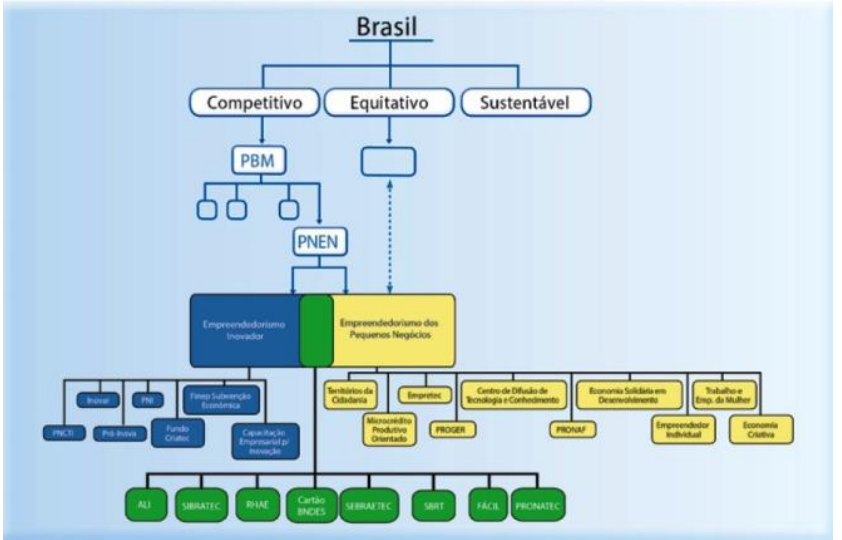

Fonte: MDIC (2012)

Para identificação das Teses e Diretrizes, além de ser enviado um questionário eletrônico para 3500 pessoas que obteve um retorno de 5,3\% (186 respostas), foram realizadas seis oficinas regionais (em Goiânia, Belém, São Paulo, Porto Alegre, Belo Horizonte, e Salvador), duas oficinas governamentais (em Brasília) e um seminário internacional, que envolveram um total de 641 participantes, dos quais $19,06 \%$ de universidades e centros de pesquisa, $20,20 \%$ de instituições especializadas de apoio ao empreendedorismo, 35,99\% do Governo, 20,85\% de Empresas e 3,91\% de crédito e capital de risco. As oficinas regionais levantaram as sugestões de ações para os 11 eixos de análise - propostos pela OCDE (ver Quadro 1) e utilizados, segundo os autores, por vários órgãos do Governo, ao passo que as oficinas governamentais levantaram os programas, projetos e ações do governo já existentes nestes eixos.

Quadro 1: Matriz para Análise do Ambiente Empreendedor

\begin{tabular}{|c|c|}
\hline NÍVEIS & EIXOS DE ANÁLISE \\
\hline \multirow{3}{*}{ MACROAMBIENTE } & Ambiente econômico \\
& Marco regulatório \\
& Governança \\
Infraestrutura \\
Internacionalização \\
\hline AMBIENTE INTERMEDIÁRIO & Educação, capacitação e disseminação \\
& Desoneração tributária e desburocratização \\
& Investimento, financiamento e crédito \\
& Tecnologia e inovação \\
\hline MICROAMBIENTE & Cultura e perfil empreendedor \\
& Empreendedorismo por segmento \\
\hline
\end{tabular}

Fonte: MDIC (2012)

\subsection{Resumo dos objetivos, critérios e resultados do estudo}

Os autores do documento ressaltam a preocupação de construir algo alinhado com as políticas federais, em especial com as diretrizes centrais do governo - conciliar o crescimento econômico com a redução das desigualdades sociais - e do Plano Brasil Maior - política industrial, tecnológica, de serviços e de comércio exterior para o período 2011-2015. Para

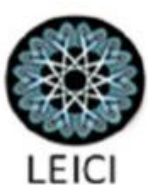


eles, o empreendedorismo constituiria "um condicionante ou um resultado, ou ambos" das metas do Plano Brasil Maior, além de se confundir e interagir de forma sinérgica com outras políticas específicas "a cargo de outros agentes governamentais" tais como a política para as micro e pequenas empresas e a política de estímulo ao empreendedorismo inovador. $\mathrm{O}$ principal objetivo da PNEN, portanto, seria "atuar na coordenação e harmonização dos instrumentos previstos para o alcance das diretrizes e dos objetivos (...) bem como na elaboração de novos instrumentos de ação que poderiam preencher possíveis lacunas identificadas".

O conceito de política pública adotado pelos autores seria o de "um campo do conhecimento (sic) que busca, ao mesmo tempo, colocar o governo (grifo nosso) em ação e/ou analisar essa ação e, quando necessário, propor mudanças no rumo ou curso dessas ações". Os autores dão destaque aos seguintes elementos que caracterizariam uma política, a saber: estabelecer o que o governo pretende fazer; envolver vários atores e níveis de ação; ser abrangente e não se limitar a leis e regras; ser uma ação intencional; e, embora tendo impactos de curto prazo, ser algo de longo prazo. Os autores definem empreendedorismo como o conjunto de esforços - individuais ou coletivos - que envolva a criação de uma base de recursos direcionados à criação de um novo negócio, incluindo atividades autônomas e criação e/ou expansão de uma empresa. Ele pode se dividir em empreendedorismo empresarial e social, conforme descrito pelo Quadro 2.

Quadro 2: Vertentes do Empreendedorismo e Impactos Esperados da PNEN

\begin{tabular}{|c|c|}
\hline \multicolumn{2}{|c|}{ VERTENTES } \\
\hline Empresarial & Social \\
\hline Geração de capital & Geração de renda \\
\hline $\begin{array}{l}\text { Empreendimentos de: } \\
\text { - Alto crescimento } \\
\text { - Inovativos } \\
\text { - Intracorporativos }\end{array}$ & $\begin{array}{cl}\text { Empreendimentos de: } \\
\text { - } \quad \text { Economia solidária } \\
\text { - Tradicionais / familiares } \\
\text { - } \quad \text { Cooperativas }\end{array}$ \\
\hline \multicolumn{2}{|c|}{ IMPACTOS ESPERADOS DA PNEN } \\
\hline $\begin{array}{l}\text { - Agregação de valor em produtos e } \\
\text { processos } \\
\text { - Incremento na pauta de exportações } \\
\text { - } \quad \text { Fortalecimento de cadeias produtivas }\end{array}$ & $\begin{array}{ll}\text { - } & \text { Desenvolvimento regional } \\
\text { - } & \text { Redução das desigualdades } \\
\text { - } & \text { Revitalização de tradições culturais }\end{array}$ \\
\hline
\end{tabular}

Fonte: MDIC (2012)

Os especialistas consultados, segundo os autores, concordavam que "o governo [teria] um importante papel a desempenhar", no sentido de "realizar as reformas que destravem os obstáculos para o desenvolvimento dos negócios e, ao mesmo tempo, estimulem a tendência ao empreendedorismo, que [teria] de tudo para se tornar um vetor decisivo para impulsionar de vez o desenvolvimento sustentável brasileiro" (itálico nosso).

Ao determinar o público-alvo da política a ser criada os autores do documento citam: jovens empreendedores, pessoas com ideias de mercado viáveis, empreendedores de setores tradicionais, empreendedores individuais, empreendedores dos setores de tecnologia de ponta e da economia criativa e, empreendedores organizados coletivamente. A Figura 2 ilustra de que forma as teses e diretrizes foram definidas.

Figura 2 - Teses e Diretrizes para a Política Nacional de Empreendedorismo - Metodologia de Consolidação
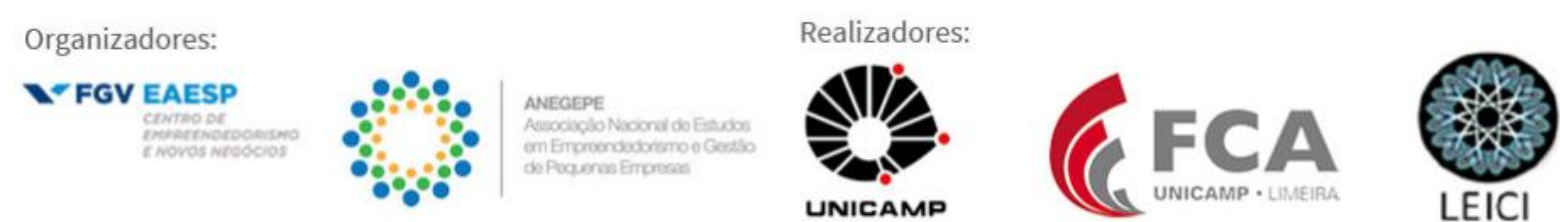


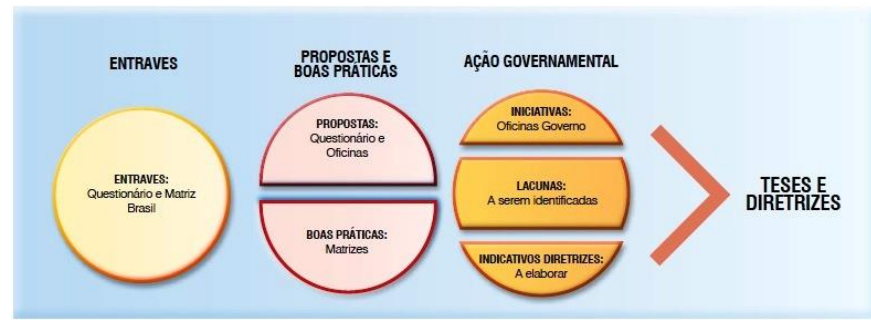

Fonte: MDIC (2012)

As 18 teses e 54 diretrizes apresentadas foram submetidas à consulta pública no período de 14 de julho a 10 de outubro de 2012, para debate e legitimação dos resultados. Foram registrados 2275 acessos ao site, dos quais $30,15 \%$ foram caracterizados como recorrentes.

Na consolidação dos resultados, foram identificados, cinco eixos (de ação) prioritários, por ordem de importância, a saber:

1. Elaboração e implantação de uma estrutura de governança que promova maior sinergia dos programas, projetos e ações já existentes;

2. Desenvolvimento e reformulação do sistema educacional em todos os níveis com abordagem transversal da pedagogia para o empreendedorismo e intraempreendedorismo;

3. Desenvolvimento de um sistema único de informações relevantes e estratégias ao empreendedor, simplificadas e organizadas a partir dos eixos estruturantes do PNEN;

4. Consolidação dos mecanismos de integração entre governo, empresa e universidade, tais como núcleos de inovação tecnológica, incubadoras, parques tecnológicos e programas de extensão, de forma a oferecer infraestrutura física e serviços estratégicos das empresas nascentes e das já existentes;

5. Desenvolvimento de um sistema eficiente de gestão, acompanhamento e avaliação de políticas públicas, de forma a otimizar recursos e potencializar os resultados. (MDIC, 2012)

Como o próprio documento ressalta (p.18), o processo de formulação de políticas públicas é "um ciclo de atividades que envolve desde planejar e desenhar a política até implementar e avaliar".

O desenho da PNEN deveria propiciar, pois, a avaliação e articulação de vários programas de apoio ao empreendedorismo e a micro e pequenas empresas já existentes, classificados, no documento, por tipo de empreendedorismo, em: inovador; de pequenos negócios; e inovador e de pequenos negócios simultaneamente, conforme apresentado no Quadro 3.

Quadro 3: Programas governamentais de apoio ao empreendedorismo

\begin{tabular}{|c|l|}
\hline Tipo de Empreendedorismo & Programas \\
\hline \multirow{2}{*}{ Inovador } & PNCTI; Inovar; Pró-Inova; PNI; Fundo Criatec; \\
& $\begin{array}{l}\text { Finep Subvenção Econômica; Capacitação } \\
\text { Empresarial para Inovação }\end{array}$ \\
\hline \multirow{2}{*}{ Pequenos Negócios } & $\begin{array}{l}\text { Territórios da Cidadania; Microcrédito Produtivo } \\
\text { Orientado; Empretec; PROGER; Centro de } \\
\text { Difusão de Tecnologia e Conhecimento; Trabalho } \\
\\
\text { e Emprego da Mulher; Economia Criativa }\end{array}$ \\
\hline \multirow{2}{*}{ Inovador e de Pequenos Negócios } & ALI; SIBRATEC; RHAE; Cartão BNDES; \\
& SEBRAETEC; SBRT; FACIL; PRONATEC \\
\hline
\end{tabular}

Fonte: Elaborado a partir da PNEN (2012) 
Uma leitura deste quadro mostra os desafios envolvidos na proposta de articulação, uma vez que os programas citados são implementados em diferentes esferas de Governo e por instituições cujas culturas são bastante diferentes.

\section{Análise do Processo de Formulação da Política Nacional de Empreendedorismo e Negócios}

\subsection{Análise do Conteúdo}

O documento apresenta uma análise do contexto à época para justificar o efeito positivo da formulação da PNEN em 2012: mercado interno pujante, estabilidade macroeconômica, bônus demográfico e mudança do ambiente corporativo, citando a inclusão de segmentos da população que viviam à margem do desenvolvimento econômico.

Nesta linha, apresenta como oportunidade para o empreendedorismo "as baixas taxas de desemprego" (p.17) por baixarem o risco do empreendedor ao lhe "dar uma perspectiva de volta ao mercado de trabalho (grifo nosso), caso o negócio não alcance o sucesso", o que denota que a elaboração da política, ao se apoiar em aspectos conjunturais favoráveis, não analisa o que está por trás dos problemas estruturais que geram a percepção ou o aumento do risco (ambiente institucional inóspito), e que poderiam ser a base para uma política de mais longo prazo.

Além disso, ao fazer a relação entre o desenvolvimento do empreendedorismo e as metas do Plano Brasil Maior lançado pelo Governo em exercício, notamos, em primeiro lugar a adoção de uma lógica instrumentalista (de apropriação) e não desenvolvimentista (de liberação), pois trata o empreendedorismo como um meio para atingir as metas do Governo e não o contrário; e, em segundo, que se faz uma confusão entre os conceitos de meta e objetivo. Qualquer planejamento estratégico faz distinção clara entre objetivos, indicadores, metas e iniciativas, onde Objetivos representam os desafios ou valores/ visões a serem enfrentados/conquistados, Indicadores servem para medir o progresso no alcance das metas e comunicam a intenção do objetivo, Metas quantificam o valor almejado para estes indicadores quando o objetivo tiver sido atingido, finalmente, as iniciativas são as ações que refletem o Como vamos chegar a atingir essas metas e que acabam por representar a estratégia propriamente dita, porque podem variar conforme os contextos.

Ao analisarmos as "metas" citadas como sendo do Plano Brasil Maior. podemos notar a confusão. Ao enunciar como meta "Ampliar o investimento fixo em \%" estamos falando de meta? de objetivo?, ou de indicador? . Além disso, das dez "metas", seis dependem única e exclusivamente, na verdade, do apoio à formação e à liberação da capacidade empreendedora do brasileiro, enquanto o Governo teria poucas ações sob sua exclusiva ou grande responsabilidade: a qualificação da mão-de-obra ou educação, o aumento da eficiência energética, e a ampliação do acesso à banda larga e outros serviços.

A análise da simples introdução do documento já nos dá sinais de problemas na visão/modus operandi do Governo para o desenvolvimento das políticas públicas no Brasil. Dois termos utilizados (apontados neste artigo por sic) no corpo do texto denotam muito da cultura do setor público brasileiro: o tratamento cidadão da forma como está inserido caracterizam a relação distante entre o Estado e a Sociedade e a implícita necessidade de tutela de um sobre o outro, assim como ao escrever sobre "fazer o que a lei prevê", mostra o crédito que se dá ao formalismo sobre a ação, como se bastasse dar uma ordem para que ela seja implementada ou funcione.
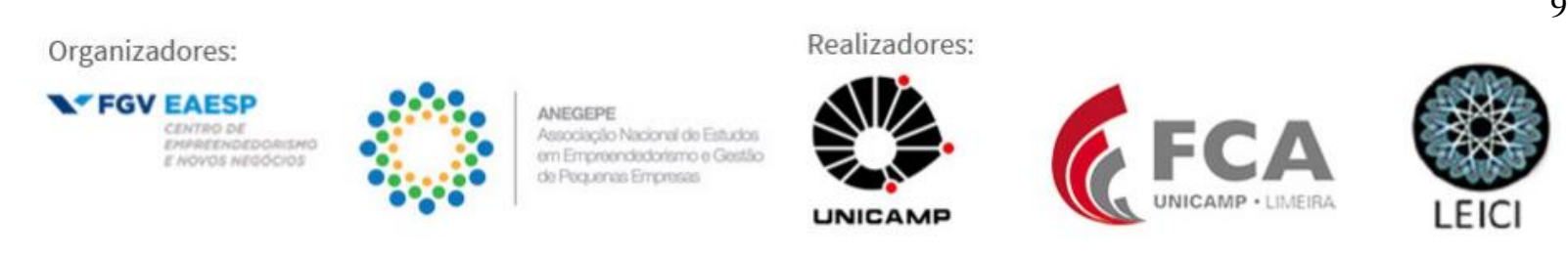
O documento tem estilo mais "acadêmico" do que executivo, se estendendo em considerações teóricas sobre conceitos de empreendedorismo e políticas públicas, tem objetivos muito abrangentes, muito recolhimento de opiniões/impressões (denominadas teses) e sugestões de ações (denominadas diretrizes) e pouco diagnóstico e, consequentemente, pouco conteúdo estratégico no sentido de direcionamento e priorização de ações e consequentemente de definição de esferas de responsabilização por desenho de programas para atingimento de metas. Aparentemente, tenta costurar uma colcha de retalhos (ações de vários órgãos), mas não se atém ou dá diretrizes para avaliar sua factibilidade, utilidade, sinergia e impactos num contexto maior.

Com vistas a promover os impactos pretendidos para a política (vide p. 8 deste artigo) a importação da Matriz para Análise do Ambiente Empreendedor (Macro ambiente, Ambiente Intermediário e Microambiente) poderia ser melhor compreendida se utilizassem algo mais intuitivo para aplicação dessas dimensões. A Figura 4 pode servir para aclarar os focos de intervenção ao se tentar realizar a terceira etapa do processo que ficou inconclusa: o desenho da política propriamente dita:

Figura 4: Segmentação para o desenho de políticas de apoio às empresas e ao empreendedorismo

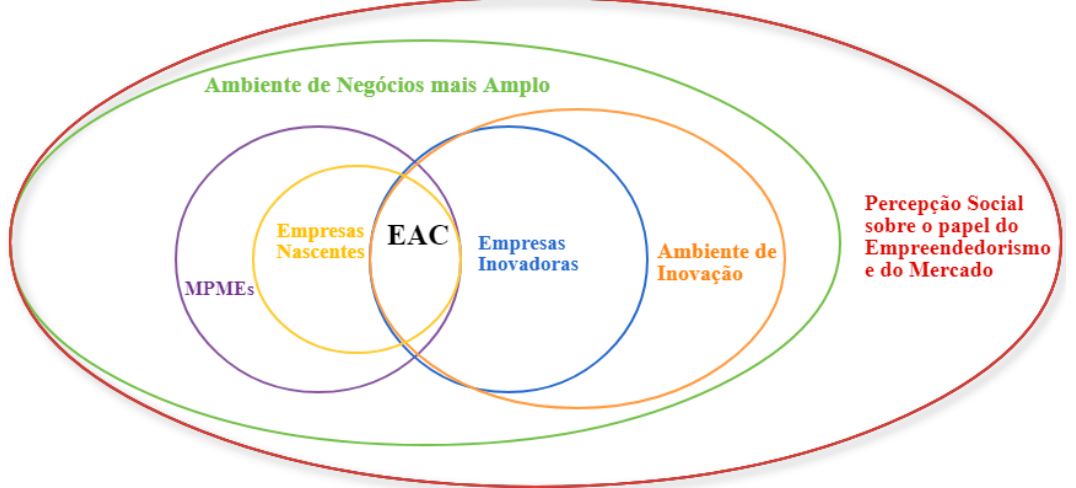

Legenda: $\mathrm{EAC}=$ Empresas de Alto Crescimento; MPMEs $=$ Micro, Pequenas e Médias Empresas

Fonte: Elaboração própria

\subsection{Análise do Contexto}

O ano de 2002 marca o início dos governos do Partido dos Trabalhadores. Estes governos, entre 2002 e 2010, foram favorecidos pelo ambiente de comércio exterior extremamente favorável no início do século XXI (Lobo e Greer, 2017). Esta tendência se manteve até o ano de formulação da PNEN. Segundo dados da Organização Mundial do Comércio, mesmo com a crise financeira que atingiu os países ocidentais em 2008 e a crise do euro em 2010, o valor do comércio global de bens e serviços teve um expressivo crescimento entre 2005 e 2012, passando de cerca de 13 trilhões de dólares para cerca de 25 trilhões (WTO, 2016). A participação do Brasil no comércio mundial, que era de 1,0\% em 2003, passa para 1,4\% em 2012 (WTO, 2013). Além disso, o país figura entre as 10 economias que mais exportam serviços no mundo, com exportações anuais superiores a 100 bilhões de dólares (WTO, 2013).

O cenário externo favorável permitiu a reprodução de um modelo particular de acumulação de capital que, aliado à implementação de políticas sociais de distribuição de renda (elevação do salário mínimo, redução da pobreza e aumento da composição do emprego formal) levou à incorporação de milhões de pessoas ao mercado de trabalho, com o fenômeno
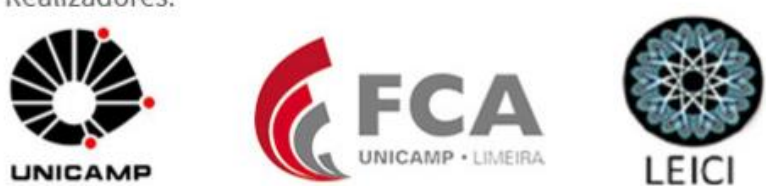
que ficou conhecido como "ascensão da nova classe média" (Lobo e Greer, 2017). Esta nova classe garantiu o dinamismo da demanda interna, centrada em serviços e bens de consumo de massa. Com isso, a taxa de desemprego caiu, de 11,1\% em 2003 para 7,8\% em 2012, segundo dados do World Economic Outlook do FMI, e a informalidade caiu de 51,6\% em 2002 para 39,3\% em 2012 (Lobo e Greer, 2017).

Este cenário de crescimento do mercado de trabalho e do PIB viria a ser interrompido a partir de 2013-14, como mostrado pelo Gráfico 1. Segundo Lobo e Greer (2017) a interrupção deste cenário está ligada ao fato que a expansão calcada no consumo interno encontra limites caso não seja acompanhada de aumento de produtividade que garanta maior acumulação de capital.

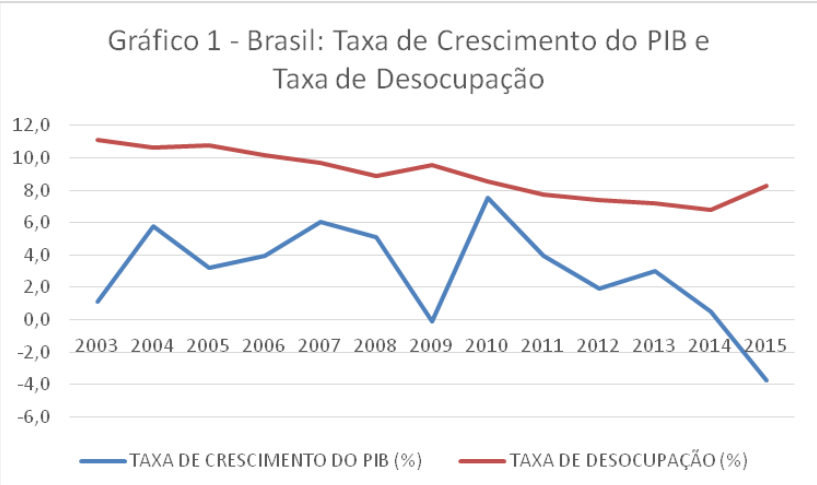

Fonte: Elaboração própria a partir de World Economic Outlook Database

Em 2008, a Lei Complementar 128/2008 criou a figura do Microempreendedor Individual (MEI). Em 2011, o projeto de lei 1673/2011, que estabelece as diretrizes e bases da educação nacional, incluiu o tema do empreendedorismo nos currículos do ensino fundamental e médio. Em 2012, ano da formulação da Política Nacional de Empreendedorismo, já havia uma percepção da retração nas taxas de crescimento do PIB, o que nos leva a propor a hipótese de que esta política foi formulada considerando o empreendedorismo como uma forma de preservar a taxa de ocupação formal e democratizar a capacidade de gerar riqueza por parte da população.

A PNEN seria a primeira tentativa de política explícita de empreendedorismo em nível federal. Sua origem é de uma demanda do poder legislativo, que já em 2003 imaginava ser a questão tão importante que deveria ser teor de leis complementares (CÂMARA, 2014). Desde o início do governo Lula até a proposição da PNEN é possível identificar, nas discussões do Congresso, uma preocupação com reformas estruturais e um aumento no interesse em assuntos relacionados a empreendedorismo e fomento a micro e pequenas empresas. Neste período observa-se também, por parte de órgãos federais de fomento como BNDES e FINEP, a definição de programas de apoio a micro e pequenas empresas como meio de promover o desenvolvimento regional. Observa-se também que um dos objetivos específicos da atuação do Ministério da Integração Nacional na política de fomento a Arranjos Produtivos Locais era disponibilizar recursos a fundo perdido para o financiamento do empreendedorismo (Lemos, Albagli e Szapiro, 2004).

O contexto político da formulação da PNEN também ajuda a explicar a sua criação. Conforme observado por Singer (2015) o ano de 2012 foi o segundo do "ensaio desenvolvimentista" do Governo Dilma, o qual foi revertido em abril de 2013. Trata-se de um
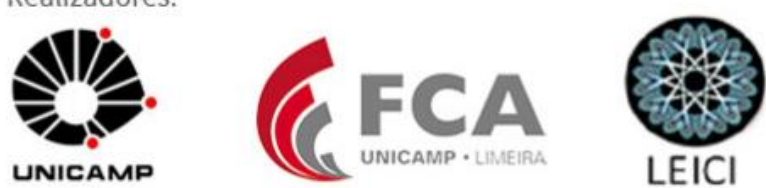
período onde o Governo buscou fomentar a atividade econômica via redução das taxas de juros a partir do diagnóstico de que a expansão do mercado interno calcada na industrialização deveria ser comandada pelo Estado, uma vez que o mercado por si só não seria capaz de promovê-la. Este ensaio durou apenas dois anos e foi substituído posteriormente por uma política contracionista visando à contenção da inflação que acabou levando à redução das taxas de crescimento do PIB mostrada pelo Gráfico 1.

Outra possível explicação para as tentativas de formulação da política é a percepção de que era necessário fomentar a criação de novas empresas, que segundo dados do IBGE caiu no período 2008-2012 (ver Gráfico 2). Esta queda, aliada ao aumento da taxa de saída das empresas, anuncia um cenário de crise no emprego que iria se confirmar nos anos seguintes.

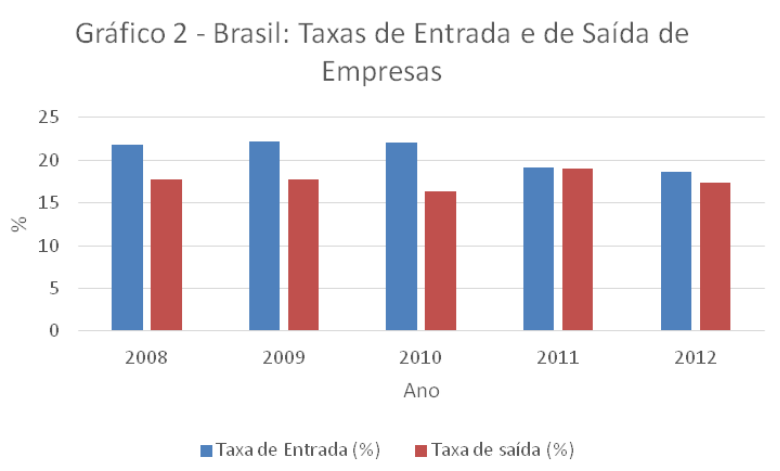

Taxa de Entrada= Relação entre número de entrada de empresas e população de empresas no ano de referência.

Taxa de Saída= Relação entre número de saída de empresas e população de empresas no ano de referência

Fonte: Elaboração Própria a partir de IBGE (2014)

\section{Discussão dos Resultados}

A existência de um documento propondo a formulação da PNEN mostra que o Governo Dilma, através do MDIC, fez uma tentativa de integrar políticas de empreendedorismo e inovação, num contexto de uma agenda política neodesenvolvimentista que não teve prosseguimento. A tentativa foi meritória por ter buscado envolver as diferentes instituições e a sociedade na sua formulação, através do mecanismo de consulta pública.

Várias razões podem explicar por que a política acabou não sendo implementada. A primeira razão, de cunho político, é a própria ruptura da agenda. A segunda razão, de ordem técnica, é a própria complexidade de articular diretrizes e programas relacionados às 18 teses identificadas.

A terceira razão, também de ordem técnica, é a falta de diagnóstico que permita avaliar e coordenar políticas e programas já existentes e dispersos por vários ministérios numa única política. A PNEN, apesar de separar empreendimentos inovativos e de alto crescimento de empreendimentos de economia solidária, não estabelece uma distinção entre políticas de empreendedorismo e políticas de inovação. Nem todas as políticas que compõem uma política de inovação podem ser consideradas como políticas de apoio ao empreendedorismo (ver Figura 5).

Figura 5: Interface entre Política de Apoio ao Empreendedorismo e Política de Inovação 


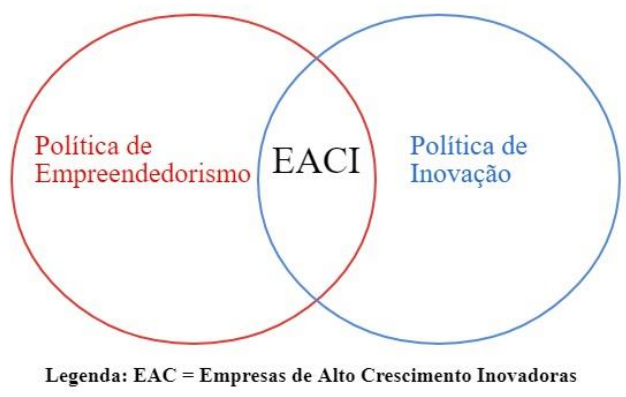

Fonte: Elaboração própria

A quarta razão se deve às dificuldades relacionadas à divisão entre empreendimentos inovativos, de alto crescimento e intracorporativos, de um lado, e empreendimentos de economia solidária, tradicionais e cooperativas, de outro. Apesar da relevância do conceito de alto crescimento para a discussão sobre o empreendedorismo, ainda não há consenso sobre como se deve medi-lo. Delmar et al. (2003) argumentam que as empresas de alto crescimento não crescem da mesma forma, e que um grande número de pesquisadores afirma que a diversidade de medidas para o conceito de crescimento impacta severamente a habilidade de comparar resultados e acumular conhecimento (Murphy et al., 1996; Weinzimmer et al., 1998). A OCDE, por exemplo, adota um conceito para alto crescimento que envolve crescimento relativo em pessoas ocupadas por três anos consecutivos, conceito este que também é adotado pelo IBGE em suas publicações (OCDE, 2009). No entanto, tal conceito se restringe a empresas com mais de 10 empregados. Clayton (2013) mostra uma alternativa ao cálculo da OCDE incluindo firmas menores, permitindo ter pelo menos alguma informação da fatia mais interessada para fins de política.

Voltando à PNEN, o apoio a empresas de alto crescimento inovadoras estaria na intersecção entre políticas de empreendedorismo e políticas de inovação, mostrada pela Figura 5. É interessante também ressaltar que a diferença entre os grupos de empresas de alto crescimento e de inovação é bastante grande. Viotti et al. (2015) apresentam as grandes diferenças existentes entre os grupos de empresas de alto crescimento (EAC), do grupo das empresas inovadoras (EI), e do grupo formado pelas empresas inovadoras e de alto crescimento no mesmo período (EACI).

Além disso, a mensuração de empreendimentos intracorporativos é tecnicamente complicada e a definição de empreendimento tradicional está ficando cada vez mais vaga, em um mundo onde soluções digitais podem ser desenvolvidas a baixo custo, e onde empreendedores de empreendimentos "tradicionais" têm estratégias competitivas semelhantes às de startups, como mostrado por Pereira e Bartholo (2015). Cabe observar que as formas de mensuração influenciam tanto nos resultados relativos (de desempenho ou de comparações transversais, por exemplo) quanto na interpretação analítica da capacidade destas empresas em alavancar a economia. Nesse sentido, qualquer escolha arbitrária de forma de mensuração delimita sua capacidade de interpretar o que é empreendedorismo.

Vale também ressaltar que as políticas de apoio ao empreendedorismo focam, na maioria das vezes, nas startups, oferecendo incentivos financeiros, em pesquisa e desenvolvimento, diminuição de tributos, estabelecimento em aceleradoras de negócios e incubadoras. A efetividade dessas iniciativas tem sido discutida, especialmente em relação aos incentivos oferecidos. Por exemplo, substituir o simples apoio financeiro por meio de

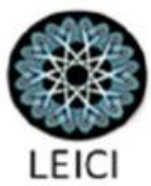


subsídios ou transferências por uma abordagem sistêmica, focada na experiência relacional e na formação de redes e conexões (networking, peer-based support, entre outros) é uma boa alternativa (Brown et al., 2014). O foco, nesta visão, passa a ser no ambiente de negócios e na interação dos diferentes agentes. Além disso, como vimos anteriormente, o conceito de startup é difícil de ser mensurado pelas estatísticas oficiais, uma vez que muitas startups nascem a partir de um grupo de pessoas empreendedoras.

Apesar de uma política que integre apoio ao empreendedorismo e à inovação fazer sentido, devido ao seu caráter sistêmico, no Brasil a taxa de inovação das empresas ainda é muito baixa: dados da PINTEC 2014 apontam que a taxa de inovação das empresas atinge no máximo 36,4\% (para empresas industriais), sendo que a inovação varia consideravelmente de acordo com o porte: enquanto empresas industriais com mais de 500 empregados reportam taxas de inovação de 65,7\%, nas empresas até 50 empregados este percentual cai para 33,4\%. Uma possível explicação para este fato é que, como observa Julien (2010):

(...) embora com certeza sejam tão capazes quanto os empreendedores ocidentais, os melhores empreendedores dos países em desenvolvimento encontram hoje dificuldades tão grandes que boa parte de sua energia é destinada a tentar encontrar os recursos de base e superar todo tipo de obstáculo, em vez de se concentrarem em aperfeiçoar a empresa e desenvolver seu mercado. (JULIEN, 2010, p.325)

Para evitar as armadilhas relacionadas à aposta nas empresas inovadoras e nas empresas de alto crescimento de um lado e nas empresas de economia solidária de outro, seria mais adequada uma política que apoiasse empresas nascentes, sem a distinção entre empresas de alto crescimento e empresas de economia solidária proposta pela PNEN. Esta proposta é universalista. Presume-se que deve haver foco nas empresas muito jovens e, portanto, todas as empresas com idade entre 0 e 4 anos devem e podem ter apoio público para passar por esse período inicial. Nos últimos anos, o fluxo de empresas saintes menos as reentradas têm colocado a taxa de saída efetiva entre $9 \%$ e $15 \%$ do total de empresas ativas (IBGE, 2014, $2015,2016,2017)$. Tais dados de demografia de empresas revelam que mais de $40 \%$ de todas as empresas morre antes de completar quatro anos de existência. Supõe-se, portanto, de que ações de políticas públicas podem ajudar a taxa de mortalidade de empresas a cair neste gap temporal. Entende-se que há uma grande oportunidade para que a ação pública, por meio de políticas, possa impulsionar as empresas nascentes para fora do período de risco extremo.

Nesta proposta, o papel das instituições de ensino e treinamento seria oferecer cursos de gestão financeira e de projetos, que já são oferecidos por instituições como Sebrae e IEL. Haveria também medidas de estímulo à obtenção de recursos (crédito, infraestrutura), apoio a networking e conexão com investidores para fortalecer o capital social das empresas, bem como medidas focadas no desenvolvimento de capacidades organizacionais das empresas.

Trata-se de uma proposta sistêmica cujo fundamento teórico segue os preceitos da teoria evolucionária, a qual considera que os agentes econômicos (empresas e instituições) constroem sua racionalidade através de interações e aprendizado coletivo, sendo este processo afetado pelas rotinas das empresas, pelos hábitos e pelas convenções da sociedade. Neste sentido, cada país ou região terá seu próprio modelo de desenvolvimento; como observado por Julien (2010, p.335) "os modelos de desenvolvimento bons para todos não existem". A rejeição à ideia de boas práticas é um desafio a ser superado pelos formuladores de política.

É fato que interesses seriam afetados por uma política deste tipo, sobretudo pela imanente resistência do sistema a mudanças estruturais. $\mathrm{O}$ que se esperaria, afinal, seria uma

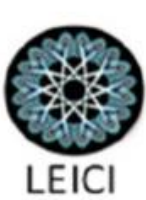


lenta mudança de trajetória que culminaria, depois de décadas, em um enraizamento da cultura do apoio às empresas nascentes.

\section{Considerações Finais}

Do ponto de vista da formulação de políticas de apoio ao empreendedorismo, o MDIC seguiu o que a literatura especializada apresentada neste artigo sugere: buscou ouvir os atores envolvidos através de audiências públicas e propôs uma abordagem sistêmica, expressa nas suas teses e diretrizes. Entretanto, o Governo não conseguiu superar os desafios à implementação mencionados neste artigo: faltou mais diálogo com os responsáveis pelo amplo leque de programas que a PNEN pretendia abranger, e seus formuladores ainda caíram na armadilha das melhores práticas ao dividir as empresas por tipo de empreendedorismo. Os resultados sugerem ainda que há uma dependência da trajetória no estabelecimento do mix de políticas, confirmando os achados da literatura internacional resenhada no presente artigo.

A complexidade na articulação de uma política sistêmica sugere que o sucesso da política depende da definição de objetivos simples, indicadores mensuráveis e metas realistas. Neste sentido, uma política sistêmica de apoio ao empreendedorismo que apoiasse empresas nascentes teria maiores chances de efetiva implementação, uma vez que possibilitaria alcançar um público mais amplo e não apenas as empresas de alto crescimento, que estão no topo da pirâmide. Uma política mais universal teria melhores condições de promover o desenvolvimento sustentável, com diminuição das desigualdades através da renovação de empresas e uma verdadeira democratização de recursos.

\section{Referências Bibliográficas}

ACS, Z. ASTEBRO, T.; AUDRETSCH, D.; ROBINSON, D. T. Public policy to promote entrepreneurship: a call to arms Small Business Economics 47, p.:35-51, 2016.

ARRUDA, C.; NOGUEIRA, V. S.; COZZI, A.; COSTA, V. Financing Innovation in Brazil: Recent Achievements and Future Challenges. In: ROVERE, R. L. L.; OZORIO, L. M. M.; MELO, L.J. (eds). Entrepreneurship in BRICS: Policy and Research to Support Entrepreneurs. Heildelberg: Springer, 2015.

BERGER, N.; UDELL, G.F The economics of small business finance: The roles of private equity and debt markets in the financial growth cycle. Journal of Banking \& Finance Vol 22 n.6, p. 613-673, 1998.

BRASIL. MINISTÉRIO DO DESENVOLVIMENTO, INDÚSTRIA E COMÉRCIO. Proposta de Teses e Diretrizes para a Política Nacional de Empreendedorismo e Negócios: Consulta Pública. Brasilia: MDIC, 2012

BRASIL. PORTAL BRASIL. País fecha 2012 com menor taxa de desemprego desde 2002. Disponível em http://www.brasil.gov.br/economia-e-emprego/2013/01/pais-fecha-2012-com-menor-taxa-de-desemprego

BROWN, R., MASON, C.; MAWSON, S. Increasing "The Vital 6 Percent": Designing Effective Public Policy to Support High Growth Firms. Nesta Working Paper 14/01, January, 2014

CARLSSON, B. Industrial Dynamics: A Review of the Literature 1990-2009. Papers in Innovation Studies Paper no. 2016/3, Lund University, January 2016.

CLAYTON, R. L. et al. High-employment-growth firms: defining and counting them. Monthly Labor Review, Washington, DC: U.S. Bureau of Labor Statistics - BLS, v. 136, n. 6, p. 3-13, June 2013.

DELMAR, F., DAVIDSSON, P. GARTNER, W.B. Arriving at the high-growth firm. Journal ofbusiness venturing 18.2 189-216, 2003.

FERREIRA, M. P. V; PINTO, C. F.; MIRANDA, R. M. Três décadas de pesquisa em empreendedorismo: uma revisão dos principais periódicos internacionais de empreendedorismo. REAd, Porto Alegre, Edição 81, $\mathrm{N}^{\circ} 2$, maio/agosto 2015, p $406-436$.

GONÇALVES, A. Políticas Públicas, etnografia e a construção dos indicadores socioculturais. Aval - Revista de Avaliação de Políticas Públicas. UFC, número 1, 2008, p. 17-28.

GUSSI, A. Apontamentos teórico-metodológicos para avaliação de programas de microcrédito. Aval - Revista de Avaliação de Políticas Públicas. UFC, número 1, 2008, p. 29-37.
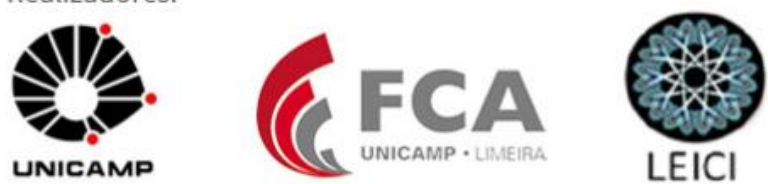
HUGGINS, R.; THOMPSON, R. Entrepreneurship, innovation and regional growth: a network theory. Small Business Economics 45, p. 103-128, 2015.

JULIEN, P.A. Empreendedorismo Regional e a Economia do Conhecimento. São Paulo: Saraiva, 2010

LEYDEN, D. P. Public-sector entrepreneurship and the creation of a sustainable innovative economy. Small Business Economics 46, p.553-564, 2016.

MALERBA, F.; TORRISI, S. La politica pubblica: In: MALERBA,F. (org.) Economia dell'Innovazione. $6^{\mathrm{a}}$ ed. Roma:Carocci Editore, 2009.

MILLER, P; BOUND, K. The Startup Factories: The rise of accelerator programmes to support new technology ventures. NESTA, 2011.

MURPHY, G. B., TRAILER, J. W., \& HILL, R. C. 1996. Measuring performance in entrepreneurship. Journal of Business Research 36: 15-23.

NIGHTINGALE, P; COAD, A. The Myth of the Science Park Economy. Demos Quarterly 2, 2014.

NISTOTSKAYA, M.; CINGOLANI, L. Bureaucratic Structure, Regulatory Quality, and Entrepreneurship in a Comparative Perspective: Cross-Sectional and Panel Data Evidence. Journal of Public Administration Research And Theory, p.519-534., 2016

ORGANIZAÇÃO PARA A COOPERAÇÃO E DESENVOLVIMENTO ECONÔMICO, Measuring entrepreneurship: a collection of indicators 2009 edition. Paris: Organisation for Economic Co-operation and Development - OECD, 2009. 62 p. OECD-Eurostat Entrepreneurship Indicators Programme. Disponível em: . Acesso em: out. 2017.

PARKER, R.; HINE, D. Enterprise Policy and the Metagovernance of Firm Capabilities Administration \& Society Vol. 47 n.6, p. $656-679,2015$

PEREIRA, I. N.; BARTHOLO, R. Entrepreneurship in Rocinha: A Non-Goal-Driven Activity. In: ROVERE, R. L. L.; OZORIO, L. M. M,; MELO, L. J. (eds). Entrepreneurship in BRICS: Policy and Research to Support Entrepreneurs. Heildelberg: Springer, 2015.

PESSALI, H. Public Policy Design in Developing Societies - Beyond Transplantation. Journal of Developing Societies, Vol 27 n.1, p; 11-28, 2011

PURI, M.; TAVOLETTI, E.; CERRUTI, C. Business Model Innovation in Emerging Economies: Leveraging Institutional Voids. In: ROVERE, R. L. L.; OZORIO, L. M. M.; MELO, L. J. (eds). Entrepreneurship in BRICS: Policy and Research to Support Entrepreneurs. Heildelberg: Springer, 2015.

ROPER, Stephen; HART, M. Supporting sustained growth among SMEs-policy models and guidelines.ERC White Paper 7, September 2013

SHANE, S. Why encouraging more people to become entrepreneurs is bad public policy. Small Business Economics Vol 33 n.2, p. 141-149, 2009

SHIRLEY, M. M. Institutions and development: advances in new institutional analysis. In: MÈNARD, C.; SHIRLEY, M.M. (Eds). Handbook of New Institutional Economics. Cheltenham, UK: Springer, 2008.

ViOTTI, E. B.; SANTOS, C. R.; CAVAlCANTE, L. R. M. T.; PINHO, R. D. E COSTA, L. R. M. (2015) Participação na economia de empresas de alto crescimento inovadoras - Uma nova família de indicadores de resultado da inovação, in Indicadores de resultado da inovação, Brasília: Centro de Gestão e Estudos Estratégicos - CGEE, pp. 143-211. 〈https://www.cgee.org.br/indicadores-de-resultado-da-inovacao > WEINZIMMER, L G.; NYSTROM, P.C.; FREEMAN, S.J. Measuring organizational growth: Issues, consequences and guidelines." Journal of Management Vol 24 n.2, p. 235-262, 1998

WINTER, S. The place of entrepreneurship in "The Economics that Might Have Been" Small Business Economics 47, p. 15-34, 2016

ZAHRA, S. A., SAPIENZA, H.J, DAVIDSSON, P. Entrepreneurship and dynamic capabilities: areview, model and research agenda."Journal of Management Studies Vol.43 n.4 p. 917-955, 2006 